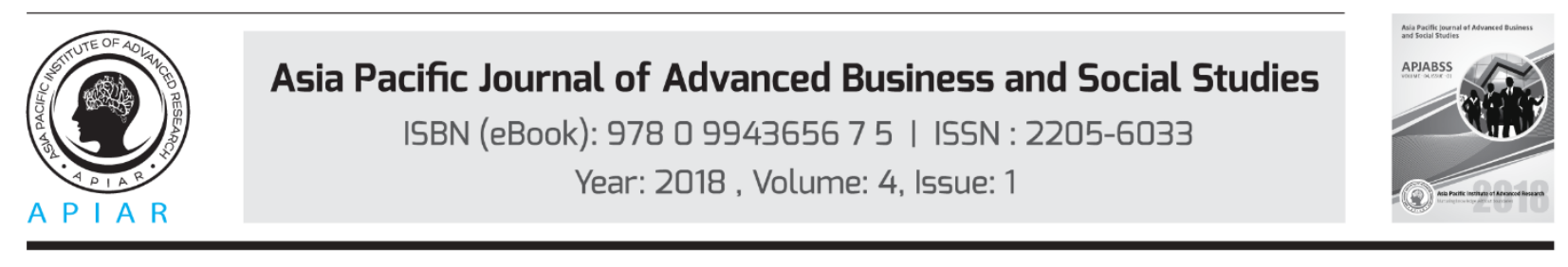

\title{
EXPLORING AN EFFECTIVE ADVERTISEMENT MEDIUM FOR THE JAPANESE COSMETICS MARKET
}

\author{
Michiko Miyamoto a, Satona Shirai ${ }^{b}$ \\ ab Akita Prefectural University, Yurihonjo, Akita, Japan \\ Corresponding email: miyamoto@akita-pu.ac.jp
}

\begin{abstract}
The cosmetics industry market is fiercely competitive in Japan as the number of different products available to consumers is continuously increasing. Since brand awareness helps the customer to buy certain products, cosmetic companies need to focus on their advertisement media. It is generally expensive to advertise, and recently, companies have moved towards new digital media such as the internet, as well as traditional media such as television and print (magazines and newspapers). The decision about which advertisement media to use in order to reach their customers becomes a big issue. This research proposes a framework for an effective advertisement medium by using survey data on Japanese cosmetic product brands. Covariance structure analysis is conducted to measure the relationship between different advertising media and consumers' purchasing intentions. In addition, advertising media, which is considered to have influenced purchases, is analysed by binomial logistic regression analysis. The research results present effective advertising media for a particular Japanese cosmetic brand.
\end{abstract}

Keywords: The Cosmetics Industry, Advertisement Media, Covariance Structure Analysis, Binomial Logistic Regression Analysis.

\section{Introduction}

Japanese women spend more per capita on cosmetics than those in any other country(Inkpen \& Ramaswamy, 2006). Japan is the second-largest cosmetics market in the world after the U.S.A., and Japanese cosmetics manufacturers are highly competitive and sophisticated (Ono, 2013).The cosmetics industry market is fiercely competitive in Japan as the number of different products available to consumers is increasing more and more. Advertisers and their agencies have always tangled with finding the most cost-effective way to deliver the right message to the right consumer (Rao et al. 2013). According to Dentsu Inc. (2016), one of the largest Japanese international advertising and public relations companies, Japan's advertising expenditures for 2016 totalled 6,288 billion yen, an increase of $1.9 \%$ compared with those of 2015.Broken down by medium, advertising expenditures for the traditional media fell in Newspapers (down 4.4\%), Magazines (down 9.0\%), while Radio (up 2.5\%) and Television (up 1.7\%; including both Terrestrial Television and Satellite Media-Related spending) increased (see Table 1). The Internet advertising market is up by $13.0 \%$, in which ads directed at smartphones, video ads, ads using new advertising technologies and data applications continued to expand. Thus, Dentsu (2016) suggests that a growth in the Internet medium will remain as the key driver for overall advertising expenditures. 
Table 1: Advertisement Cost in Japan, 2016

\begin{tabular}{lrr}
\hline Advertising Medium & $\begin{array}{r}\text { Advertisement Cost } \\
\text { (in billion yen) }\end{array}$ & $\begin{array}{r}\text { Compared } \\
\text { to 2015 }\end{array}$ \\
\hline Newspapers & 543.1 & $95.60 \%$ \\
Magazine & 222.3 & $91.00 \%$ \\
Radio & 128.5 & $102.50 \%$ \\
TV media & $1,965.7$ & $101.70 \%$ \\
Terrestrial broadcasting & $1,837.4$ & $101.60 \%$ \\
Satellite broadcasting & 128.3 & $103.90 \%$ \\
Mass communication media & 306.1 & $99.80 \%$ \\
Internet media & $1,310.0$ & $113.00 \%$ \\
\hline
\end{tabular}

\section{(The auther created the table based on data from Dentsu, \\ http://www.dentsu.co.jp/knowledge/ad_cost/2016/media2.html, Retrieved on May 9, 2017)}

The decision about which advertisement media to use in order to reach their customers effectively becomes a big issue. This research proposes a framework for an effective advertisement medium by using survey data on one of popular Japanese cosmetic product brand, "MAQuillAGE." Covariance structure analysis is conducted to measure the relationship between different advertising media, consumers' purchasing intentions and actual purchases. In addition, advertising media, which is considered to have influenced purchases, is analysed by binomial logistic regression analysis. The research results present effective advertising media for a particular Japanese cosmetic brand.

\section{Literature Review}

Consumers' shopping behaviors and product choices are influenced by product values (Zeithaml, 1988). At the same time, advertising value, a representation of the perceived value of advertising to consumers, is also suggested as an important determinant of consumer response (Ducoffe, 1995). Advertisers and their agencies generally think that media differentially impact the effectiveness of advertising and media context has an important influence on advertising value (Ducoffe, 1995). As mentioned in the previous section, there is a wide range of advertising methods that advertisers can choose to promote their products, and each advertising medium has its advantages and disadvantages. Questions are which media will be most effective for appealing to their targeted consumers.

There are some literature studies which focus on the differences in media characteristics between traditional media and the internet. In the earlier study, Yoon and Kim (2001) found that internet advertising is better suited for highly involved, as well as rationally oriented consumers and that the internet should be recognized as an important media alternative in view of its preference and effectiveness of advertising excution. Effects of information, entertainment, and irritation on various on-line consumer behaviours, such as attitude toward the site, Internet usage, and satisfaction have known (Luo, 2002).

As for the effect of the advertisement and the promotion in Japanese market, the Internet commercials have expanded to the second media following the television commercials, and the synegistic effect between the Internet commercials and the traditional media such as the TV commercials are seen (Yamada et al., 2015). 
Marketing of brands through word-of-mouth (WOM) is one of the common branding methods that could enhance the brand's characteristics. Compared to traditional advertising,WOM or electronic word-of-mouth marketing, electronic word-of-mouth communication (eWOM) behavior continues to grow in importance in consumer awareness, trial, and purchase of new products. WOM is definded as an "informal, person to person communication between a perceived non-commercial communicator and a receiver regarding abrand, a product, an organization or a service" (Harrison-Walker, 2001). WOM communication is increasingly regarded as one ofthe significantfactors influencing consumer decisions (Carroll and Ahuvia, 2006; Datta et al., 2005; Goldenberget al., 2001). Earlier research has shown that WOM has more impact than traditional marketingtools (Katz and Lazarfeld, 1955). WOM and eWOM can be triggered by Consumer-generated media (CGM) (Wiedemann, 2015.). CGM, also called usergenerated Web sites or social media, includes YouTube, blog entries, consumer email feedback, message board posts, forum comments, personal Web sites, personal e-mail, wikis, raves, profiles, networks, and mailing lists (Hart and Blackshaw, 2006). CGM is created and driven by consumers and is advancing as a major consumer resource and activity (Dickey and Lewis, 2007).

Within consumer behavior research (e.g., Sheppard et al., 1988; Taylor andTodd, 1995; Davis et al., 2002; Venkatesh and Davis, 2000; Venkatesh et al., 2003), the positivelink between the actual behavior and intention have been reported. Theory of Planned Behavior (Ajzen, 1991) emphasis in the link between beliefs andbehavior and it has been applied to studies of the relation among beliefs, attitudes, behavioralintention and behavior (see Figure 1).

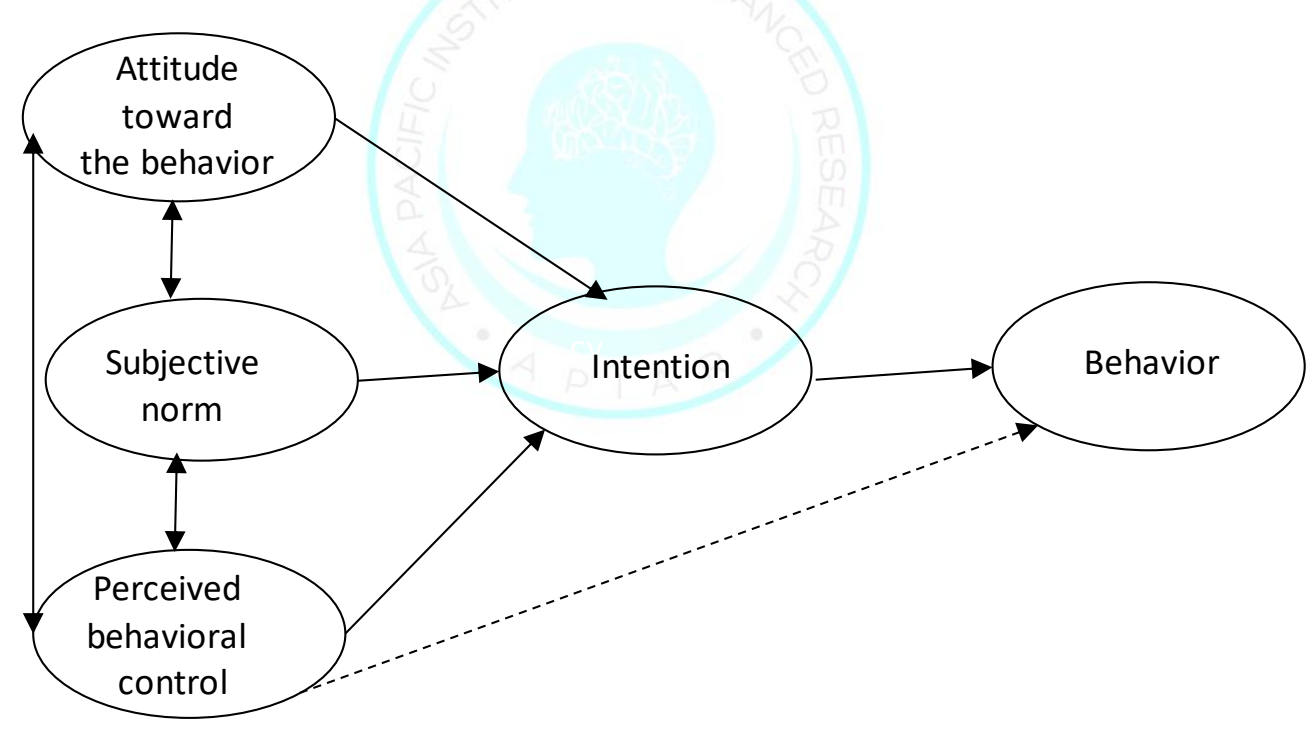

Figure 1: Theory of Planned Behavior (TPB); Source: Ajzen (1991)

Consumer behavior now suggests that shoppers browse and buy on various channels. In other words, consumer behavior is becoming more omnichannel, and how will retailers alter their merchandising and channel strategies to better attract customers and provide that seamless omni-channel experience (Wallace, 2017). 


\section{Methods}

This research proposes a research model, as shown in Figure 2, to examinethe relationships between different advertisingmedia, intention to buy, and actual purchaseactivities of consumersin the cosmetic industry.

This research was conducted using single-source data provided by Nomura Research Institute, Ltd, one of the largest consulting firms in Japan. Single-source data is data that measures media exposure and transaction information for the same people(Rao et al. 2013). The data in this study is composed of "the marketing activity" such as advertisements of products and "Process of consumer behavior."The dataset contains a collection of 3,000 consumers, including 1,545 males and 1,455 females,during the period from January 30 to April 2, 2016. Since this paper analyses consumers' purchasing activities in "MAQuillAGE", the authors focus only on the female respondents at this time. "MAQuillAGE" is one of six global brands/linesproducedby Shiseido, offering a wide variety of beauty products from skincare to makeup. “MAQuillAGE”brand products are mid-priced cosmetics, marketing through voluntary chain stores, department stores, drugstores, general merchandise stores, known for vibrant colors and beautiful packaging.After removing any missing values, there were 933 respondents available for the analysis. A list of variables is shown in Table 2, and descriptive statistics of the data is shown in Table 3.Table 4 contains the Pearson correlation coefficient between all pairs of thirteen variables with the two-tailed significance of these coefficients. All variables correlate fairly well and are statistically significant, and none of the correlation coefficients are particularly large; therefore, multicollinearity is not a problem for these data.

Table 2:A List of Variables

\begin{tabular}{|c|l|}
\hline $\begin{array}{c}\text { FREQUENCY of USE } \\
\text { CGM (Twitter, Facebook, } \\
\text { YouTube, niconico) }\end{array}$ & $\begin{array}{l}\text { if a consumer was in constant use (everyday) or use once in a way (once a week) then one (1) } \\
\text { if a consumer is infrequently use (hold an account), know the name (do not have an account), or do not know then zero (o) }\end{array}$ \\
\hline TV PROGRAM & a dummy variable indication whether a consumer watched the particular TV program or not \\
\hline $\begin{array}{c}\text { FREQUENCY OF TV } \\
\text { VIEWINGS }\end{array}$ & $\begin{array}{l}\text { a dummy variable indication whether a consumer never watched the particular TV program } \\
\text { a dummy variable indication whether a consumer watched the particular TV program ten to nineteen (10-19) times } \\
\text { a dummy variable indication whether a consumer watched the particular TV program twenty to twenty-nine (20-29) times } \\
\text { a dummy variable indication whether a consumer watched the particular TV program thirty to thirty-nine (30-39) times }\end{array}$ \\
\hline WEBSITE & a dummy variable indication whether a consumer accessed to the particular WEBSITE or not \\
\hline MAGAZINE & $\begin{array}{l}\text { a dummy variable indication whether a consumer read the particular magazine or not } \\
\text { a dummy variable indication whether a consumer bought products within a month or not } \\
\text { a dummy variable indication whether a consumer try products within a month or not } \\
\text { a dummy variable indication whether a consumer just looked at products in shop within a month or not } \\
\text { a dummy variable indication whether a consumer know the name of products } \\
\text { a dummy variable indication whether a consumer do not know the products }\end{array}$ \\
\hline
\end{tabular}


Table 3: Descriptive Statistics for Female Respondents

\begin{tabular}{|c|c|}
\hline Age & $20 s=316,30 s=421,40 s=382,50 s=336$ \\
\hline Marital Status & Single $=508$, Married $=873$, Divocee $=74$ \\
\hline Having any children & yes $=652$, no $=803$ \\
\hline \multirow{3}{*}{ Household status } & Single $=220$, Husband \& wife $=260$, Husband \& wife $\&$ unmarried children $=726$ \\
\hline & A single parent \& unmarried children, Husband \& wife and married children $=15$ \\
\hline & Three generations $=86$, others $=37$ \\
\hline \multirow{6}{*}{ Income Status } & no income $=24$; Less than 1 million yen $=49 ; 1$ million yen $\sim 2$ million yen $=70$ \\
\hline & 2 million yen $\sim 3$ million yen $=145 ; 3$ million yen $\sim 4$ million yen $=163$ \\
\hline & 4 million yen $\sim 5$ million yen $=199 ; 5$ million y en $\sim 6$ million y en $=190$ \\
\hline & 6 million y en $\sim 7$ million y en $=130 ; 7$ million y en $\sim 10$ million y en $=276$ \\
\hline & 10 million yen $\sim 15$ million yen $=151 ; 15$ million yen $\sim 20$ million yen $=35$ \\
\hline & More than 20 million yen $=22$ \\
\hline
\end{tabular}

Based on the consumer behaviour theory and theory of planned behaviour, the author would like to propose the research model to investigate the relationships between consumers' intention to buy, actual purchases activities and different media, i.e., women's magazine (ViVi, CanCam, VoCE), cosmetics' related website ("@cosme", a Consumer Generated Media on beauty and cosmetics, and "Watashi Plus", a web service by Shiseido) and CGM (Twitter, Facebook, YouTube, Niconico). Figure 2 depicts the proposed framework.

Table 4: A Correlation Matrix

\begin{tabular}{|c|c|c|c|c|c|c|c|c|c|c|c|c|c|}
\hline & $\begin{array}{l}\text { Intention } \\
\text { to buy } \\
\text { MAQuillAGE } \\
\text { (March 17) }\end{array}$ & $\begin{array}{c}\text { Actual } \\
\text { purchase of } \\
\text { MAQuillAGE } \\
\text { (March 17) }\end{array}$ & $\begin{array}{l}\text { Intention } \\
\text { to buy } \\
\text { MAQuillAGE } \\
\text { (March 29) }\end{array}$ & $\begin{array}{c}\text { Actual } \\
\text { purchase of } \\
\text { MAQuillAGE } \\
\text { (March 29) } \\
\end{array}$ & Twitter & Facebook & YouTube & Niconico & @ cosme & $\begin{array}{l}\text { Watashi } \\
\text { plus }\end{array}$ & ViVi & $\begin{array}{c}\text { Can Cam } \\
\text { (Feburary } \\
23)\end{array}$ & $\begin{array}{c}\text { VocE } \\
\text { (Feburary } \\
{ }_{23} \text { ) }\end{array}$ \\
\hline Intention to buy MAQuillAGE (March 17) & 1 & $.4166^{11}$ & $.767^{\prime \prime \prime}$ & $.406 "$ & $.094^{\prime \prime}$ & $.095^{\circ "}$ & .093 & 0.059 & -0.013 & 0.061 & $.069^{\circ}$ & 0.058 & $.077^{\circ}$ \\
\hline Actual purchase of MAQuillAGE (March 17) & $.416^{\circ "}$ & 1 & $.410^{\circ *}$ & $.680^{* \prime}$ & $.078^{*}$ & $128 *$ & $.085^{* \prime}$ & $.097^{* *}$ & 0.011 & $.073^{\circ}$ & 0.015 & 0.045 & 0.056 \\
\hline Intention to buy MAQuillAGE (March 29) & $.767^{\circ "}$ & $.410^{* *}$ & 1 & $.472^{* *}$ & $.107^{* *}$ & $.116^{6 "}$ & $.121{ }^{*}$ & $.084^{* *}$ & 0.009 & $.086 "$ & -0.037 & 0.022 & $.065^{*}$ \\
\hline Actual purchase of MAQuillAGE (March 29) & $.4066^{*}$ & $.680^{\circ}$ & $.472^{*}$ & 1 & $.081^{\circ}$ & 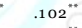 & $.065^{\circ}$ & $.066^{\circ}$ & $.105^{* *}$ & $.093^{*}$ & 0.046 & 0.041 & $.068^{*}$ \\
\hline Twitter & .094 & $.078^{\circ}$ & $.107^{* *}$ & 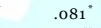 & 1 & $.414^{-1}$ & $.346^{* 1}$ & $.388^{*}$ & $.073^{\circ}$ & 0.002 & 0.022 & 0.031 & 0.027 \\
\hline Facebook & $.095^{\circ "}$ & $.128^{*}$ & $.116^{* \prime}$ & $.102 "$ & .414 & 1 & $.243^{*}$ & $.130^{\circ}$ & 0.054 & 0.010 & $.078^{*}$ & $.072^{*}$ & 0.048 \\
\hline YouTube & $.093^{*}$ & $.085^{*}$ & $.121^{* *}$ & $.065^{\circ}$ & $.346^{*}$ & 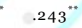 & 1 & $.400 "$ & 0.018 & $-.070^{\circ}$ & 0.002 & 0.003 & 0.064 \\
\hline Niconiko & 0.059 & .097" & $.084^{* *}$ & $.066^{\circ}$ & $.388^{* \prime}$ & $.130^{\circ "}$ & $.400^{* 1}$ & 1 & 0.037 & -0.028 & -0.023 & -0.016 & 0.033 \\
\hline$@$ cosme & -0.013 & 0.011 & 0.009 & $.105^{* *}$ & $.073^{\circ}$ & 0.054 & 0.018 & 0.037 & 1 & $.076^{\circ}$ & -0.006 & -0.009 & -0.012 \\
\hline Watashi plus & 0.061 & $.073^{*}$ & $.086 *$ & $.0933^{* *}$ & 0.002 & 0.010 & $-.070^{*}$ & -0.028 & $.076^{\circ}$ & 1 & -0.004 & -0.006 & -0.008 \\
\hline ViVi & $.069^{\circ}$ & 0.015 & -0.037 & 0.046 & 0.022 & $.078^{*}$ & 0.002 & -0.023 & -0.006 & -0.004 & 1 & $.352^{* *}$ & -0.004 \\
\hline Can Cam (Feburary 23) & 0.058 & 0.045 & 0.022 & 0.041 & 0.031 & $.072^{\circ}$ & 0.003 & -0.016 & -0.009 & -0.006 & $.352^{*}$ & 1 & $.375^{\circ}$ \\
\hline VoCE (Feburary 23) & $.077^{*}$ & 0.056 & $.065^{*}$ & $.068^{*}$ & 0.027 & 0.048 & 0.064 & 0.033 & -0.012 & -0.008 & -0.004 & $.375^{* *}$ & 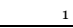 \\
\hline
\end{tabular}

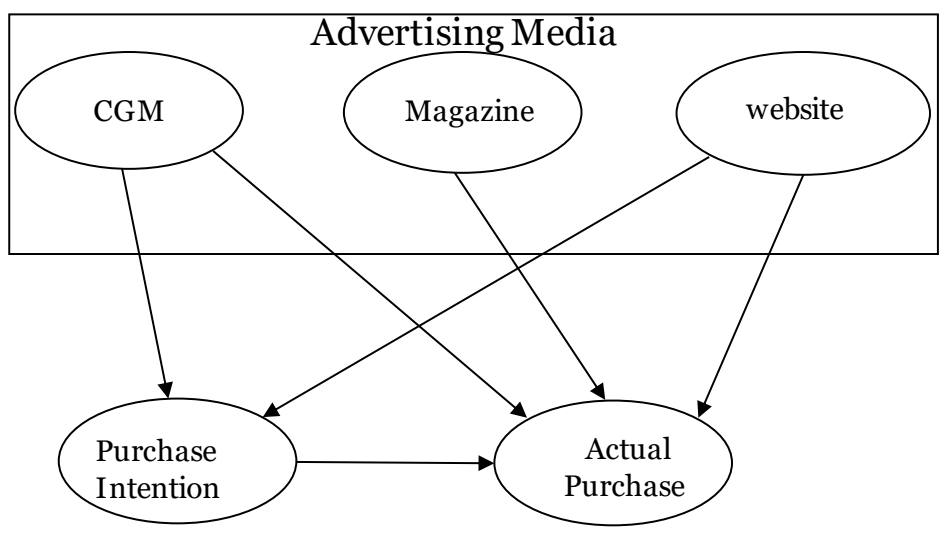

Figure 2: A Research Model

Asia Pacific Institute of Advanced Research (APIAR)

DOI : 10.25275/apjabssv4i1bus4 
Then, the authors had formed the following sixhypotheses:

H1: There is a significant, positive relationship betweenadvertisement on magazine and actual purchase

H2: There is a significant, positive relationship betweenadvertisement on cosmetics' related website and purchase intention

H3: There is a significant, positive relationship betweenadvertisement on cosmetics' related website and actual purchase

H4: There is a significant, positive relationship betweenadvertisement on CGM and purchase intention

$\mathrm{H}_{5}$ : There is a significant, positive relationship betweenadvertisement on CGM and actual purchase

H6: There is a significant, positive relationship betweenconsumers' intention to purchase and actual purchase

\section{Results}

\section{4-1. Covariance structure analysis}

Testing the efficacy of the covariance structure analysis was conducted by AMOS 24, and the major results of analysisare shown in figure 3. The path diagram highlights the structural relationships. In this diagram, the measured variables are enclosed in boxes, latent variables are circled and arrows connecting two variables represent relations, and open arrows represent errors.

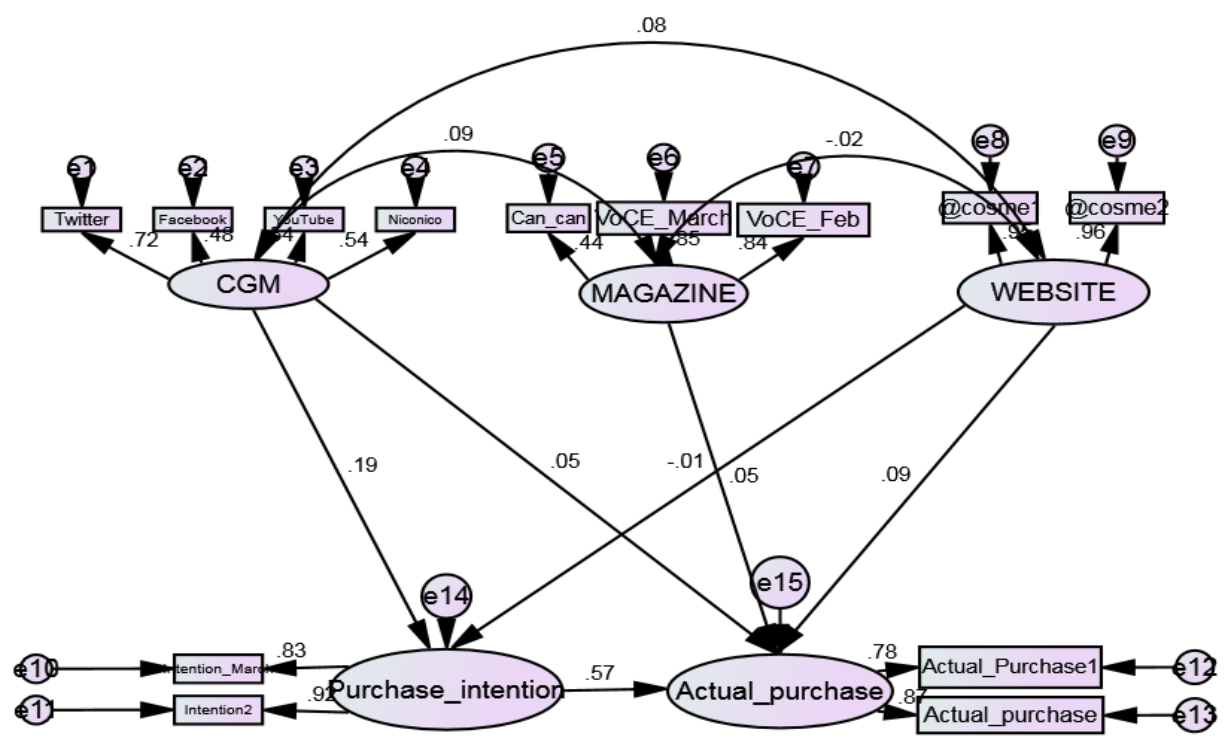

Figure 3: The path diagram of covariance structure analysis

When a covariance structure analysis is used to verify a theoretical model, a better goodness of fit is required (Byrne, 2010); the better the fit, the closer the model matrix and the sample matrix. By means of various goodness-of-fit indexes, including the comparative fit index (CFI) (Byrne, 2010), the incremental fit index (IFI) (Byrne, 2010), and the root mean squared error of approximation (RMSEA) (Browne and R.Cudeck,1993), the estimated matrix can be evaluated Asia Pacific Institute of Advanced Research (APIAR)

DOI : 10.25275/apjabssv4i1bus4 
against the observed sample covariance matrix to determine whether the hypothesized model is an acceptable representation of the data. In general, incremental fit indexes (i.e., CFI, IFI) above 0.90 signify good model fit.RMSEA values lower than 0.08 signify acceptable model fit, with values lower than 0.05 indicative of good model fit (Browne and R.Cudeck,1993). The research model is shown in figure 3; $\mathrm{CFI}=0.982$, IFI=0.982, RMSEA=0.029 (see table 6). The Path Coefficient for the research model suggested that the regression coefficient for most of constructs show significance. Since all of the indexes satisfy the cut-off values, these results are regarded as acceptable.

Table 5:The Path Coefficients of The Research Model

\begin{tabular}{|c|c|c|c|c|c|c|c|}
\hline \multicolumn{3}{|l|}{ Construct } & \multirow{2}{*}{$\begin{array}{c}\begin{array}{c}\text { Std. } \\
\text { Weight }\end{array} \\
0.188\end{array}$} & \multirow{2}{*}{$\begin{array}{c}\begin{array}{c}\text { Unstd. } \\
\text { Weight }\end{array} \\
0.163\end{array}$} & \multirow{2}{*}{$\begin{array}{l}\text { S.E. } \\
0.037\end{array}$} & \multirow{2}{*}{$\begin{array}{c}\begin{array}{c}\text { C.R. } \\
\text { (t-value) }\end{array} \\
4.393\end{array}$} & \multirow{2}{*}{$\frac{\text { P Value }}{* * *}$} \\
\hline Purchase intention & $<---$ & CGM & & & & & \\
\hline Purchase intention & $<---$ & WEBSITE & -0.013 & -0.007 & 0.019 & -0.355 & 0.722 \\
\hline Actual purchase & $<---$ & WEBSITE & 0.089 & 0.031 & 0.011 & 2.745 & 0.006 \\
\hline Actual purchase & $<---$ & MAGAZINE & 0.046 & 0.842 & 0.623 & 1.352 & 0.176 \\
\hline Actual purchase & $<---$ & Purchase intention & 0.572 & 0.372 & 0.029 & 12.874 & $* * *$ \\
\hline Actual purchase & $<---$ & CGM & 0.045 & 0.025 & 0.022 & 1.164 & 0.244 \\
\hline Twitter & $<---$ & CGM & 0.724 & 1 & & & \\
\hline Facebook & $<---$ & CGM & 0.481 & 0.646 & 0.062 & 10.489 & $* * *$ \\
\hline YouTube & $<---$ & CGM & 0.544 & 0.665 & 0.059 & 11.258 & $* * *$ \\
\hline Niconico & $<---$ & CGM & 0.536 & 0.555 & 0.05 & 11.17 & $* * *$ \\
\hline Can Cam & $<---$ & MAGAZINE & 0.444 & 1 & & & \\
\hline VoCE March & $<---$ & MAGAZINE & 0.846 & 2.517 & 0.207 & 12.179 & $* * *$ \\
\hline VoCE February & $<---$ & MAGAZINE & 0.842 & 2.504 & 0.205 & 12.219 & $* * *$ \\
\hline$@$ Cosme1 & $<---$ & WEBSITE & 0.951 & 1 & & & \\
\hline$@$ Cosme2 & $<---$ & WEBSITE & 0.961 & 0.97 & 0.118 & 8.223 & $* * *$ \\
\hline Intention March1 & $<---$ & Purchase intention & 0.922 & 1 & & & \\
\hline Intention March2 & $<---$ & Purchase intention & 0.833 & 0.85 & 0.041 & 20.883 & $* * *$ \\
\hline Actual purchase March1 & $<---$ & Actual purchase & 0.778 & 1 & & & \\
\hline Actual purchase March2 & $<---$ & Actual purchase & 0.874 & 1.185 & 0.068 & 17.389 & $* * *$ \\
\hline
\end{tabular}

Table 6: Reliability Test

\begin{tabular}{llc} 
FIT indices & Recommended level & Research Model \\
\hline CMIN/DF & 5.0 (Wheaton et al, 1977) 2.0 (Tabachnick and Fidell, 2007). & 2.163 \\
CFI & $>0.90$ (Bentler, 1990) & 0.982 \\
IFI & $>0.90($ Bollen, 1989) & 0.982 \\
RMSEA & $<0.10$ (MacCallum, et al.1996) & 0.029 \\
AIC & Smaller values suggest a good fitting (Akaike, 1974) & 382.216 \\
p-value & $>0.05$ & 0.000 \\
\hline
\end{tabular}

A result of the research model for the relationships between consumers' intention to buy, actual purchase activities and different types of media, i.e., women's magazine, cosmetics' related website and CGM in Japan show the following six findings:

H1: There is a positive,but not significant relationship betweenadvertisement on magazine and actual purchase 
H2: There is a negative and not significant relationship betweenadvertisement on cosmetics' related website and purchase intention

H3: There is a significant, positive relationship betweenadvertisement on cosmetics' related website and actual purchase

H4: There is a significant, positive relationship betweenadvertisement on CGM and purchase Intention

$\mathrm{H}_{5}$ : There is a positive but not significant relationship betweenadvertisement on CGM and actual purchase

H6: There is a highly significant, positive relationship betweenconsumers' intention to purchase and actual purchase

The results of covariance structure analysissuggest that there are strong relationships between cosmetics' related website and actual purchase of "MAQuillAGE," and CGM has a stronginfluence on the purchase intention of consumers. And as previous studies reported, a highly significant, positive relationship betweenconsumers' intention to purchase and actual purchase was seen for this analysis.

\section{4-2. Binomial Logistic Regression Analyses}

A binomial logistic regression predicts the probability that an observation falls into one of two categories of a dichotomous dependent variable based on one or more independent variables that can be either continuous or categorical.

4-2-1. Analysis 1

The relationships between browsing frequencies of each advertisement media and consumers' purchase intention were analyzed by a binomial logistic regression analysis. The result is shown in Table 7.

Table 7: The result of binomial logistic regression analysis 1

(Dependent variable=purchase intention)

\begin{tabular}{llc}
\hline \multicolumn{1}{c}{ Media } & & Estimated Value \\
\hline \multirow{3}{*}{ SNS } & Twitter & $1.2053^{* *}$ \\
& Niconico & $1.0123^{*}$ \\
& No contact & -5.2183. \\
\hline \multirow{2}{*}{ Frequencies (TV programs) } & $1-9$ (times) & -4.1812 \\
& $10-19$ & -3.8023 \\
& $20-29$ & -3.4114 \\
& $30-39$ & $-6.2066^{*}$ \\
\hline \multirow{2}{*}{ Cosmetics' websites } & Watashi plus & $4.2301^{*}$ \\
& @cosme & $-3.0521^{* *}$ \\
\hline \multirow{2}{*}{ Women's magagines } & ViVi & -23.2696 \\
& Mart & 6.1499 \\
& MORE & $5.4569^{* *}$ \\
\hline
\end{tabular}


4-2-2. Analysis 2

The relationships between browsing frequencies of each advertisement media without TV commercials and purchase intention were analyzed again by the binomial logistic regression analysis (see Table 8). TV commercial was omitted at this time because much influence of each TV programs was not seen on purchase intentions, according to the results of analysis 1.

Table 8: The result of binomial logistic regression analysis 2

(Dependent variable=purchase intention)

\begin{tabular}{lc}
\hline \multicolumn{1}{c}{ Media } & Estimated Value \\
\hline Twitter & $0.6378^{* *}$ \\
Frequencies (TV programs): & $-1.2728^{*}$ \\
Watashi plus & 2.632 \\
@cosme & $-1.2358^{*}$ \\
ViVi & -14.8044 \\
Mart & 1.5857 \\
\hline
\end{tabular}

4-2-3. Results of Binomial Logistic Regression Analyses

The main aim for binomial logistic analyses was to investigate the relationship between different advertising media and consumers' purchase intentions. Analysis 1 shows the overall relevance of these on SNS (Twitter and Niconico), Watashi Plus, and women's magazines, Mart and More. Analysis 2 shows that Twitter is considered to be the most positive influence over purchase intentions.

\section{Conclusion}

This research proposes a framework for an effective advertisement medium by using survey data on Japanese cosmetic product brand, "MAQuillAGE."A covariance structure analysis is conducted to measure the relationship between different advertising media and consumers' purchasing intentions. The results of covariance structure analysis suggest that there are strong relationship between cosmetics' related website, such as "Watashi plus," and actual purchase of "MAQuillAGE." CGMs, such as Twitter and Niconico, havestrong influences over purchase intention of consumers. And as previous studies reported, there is a highly significant, positive relationship betweenconsumers' intention to purchase and actual purchase as well.

In addition, a relationship between intention to purchase and advertising media, which is considered to have influence on purchases, is analysed by binomial logistic regression analyses. The research results present Internet, such as SNS and CGM are effective advertising media for a particular Japanese cosmetic brand. 


\section{References}

i. Ajzen, I., 1991. The Theory of Planned Behavior. Organizational Behavior and Human DecisionProcesses, Volume 50, pp. 179-211.

ii. Akaike, H., 1974. A New Look at the Statistical Model Identification. IEE Transactions on Automatic Control, 19(6), pp. 716-723.

iii. Bollen, K., 1990. Overall Fit in Covariance Structure Models:Two Types of Sample Size Effects. Psychological Bulletin, 107(2), pp. 256-59.

iv. $\quad$ Browne, M. \& Cudeck, R., 1993. Alternative Ways of Assessing Model Fit. Sociological Methods and Research, Volume 21, pp. 230-239.

v. Byrne, B., Basic concepts, applications, and programming. Structural equation modeling using AMOS”. 2nd ed. New York: Routledge.

vi. Carroll, B. \& Ahuvia, A., 2006. Some antecedents and outcomes of brand love. Market Letters, Volume 17, pp. 79-89.

vii. Datta, P., Chowdhury, D. N. \& Chakraborty, B. R., 2005. Viral marketing: New form of wordofmouth through Internet. The Business Review, 3(2), pp. 69-75.

viii. $\quad$ Dentsu, 2016. Advertising Expenditures in Japan. [Online] Available at: http://www.dentsu.com [Accessed 9 May 2017].

ix. $\quad$ Dickey, I. \& WF.Lewis, 2007. Consumer-Generated Media (CGM):An Exploratory Study ofVarious Forms, Value to Consumers, and Marketing Practitioners, and Global Implications, s.l.: Management and Marketing Faculty Publications.

x. Harrison-Walker, L., 2001. The measurement of Word-ofMouth communication and aninvestigation of service quality and customer commitment as potential antecedents. Journal of Service Research, 4(1), pp. 60-75.

xi. $\quad$ Hart, Christopher \& Blackshaw, P., 2006. "Internet Inferno,"Marketing Management, s.l.: s.n.

xii. $\quad$ Inkpen, A. \& Ramaswamy, K., 2006. Global Strategy: Creating and Sustaining Advantage across Borders, New York.: Oxford University Press.

xiii. J.Davies, Foxal, R. \& J.Pallister, 2002. Beyond the Intention-Behaviour Mythology: An Integrated Model of Recycling. Marketing Theory, 2(1), pp. 29-113..

xiv. J.Goldenberg, B.Libai \& Muller, E., 2001. Talk of the Network: A Complex Systems Look at the Underlying Process of Word-of-Mouth. Marketing Letters, 12(3), p. 211-223.

xv. Jöreskog, K. \& D.Sörbom, 1993. Structural Equation Modeling with the SIMPLIS Command Language, Chicago: Scientific Software International Inc..

xvi. $\quad$ Katz, E. \& Lazarfeld, P., 1955. Personal Influence, Glencoe: Free Press.

xvii. Luo, X., 2002. Uses and Gratifications Theory and E-Consumer Behaviors A Structural Equation Modeling Study. Journal of Interactive Advertising, 2(2), pp. 34-41.

xviii. MacCallum, R., M.WBrowne \& Sugawara, H., 1996. Power Analysis and Determination of Sample Size for Covariance Structure Modeling. Psychological Methods, 1(2), pp. 130-49.. 
xix. Ono, C. Y., 2013. Cosmetics Market Overview, U.S, s.l.: Commercial Service, United Stated of America, Department of Commerce..

xx. Rao, K., M.Sneathen, Bradbury, N. \& Nazzaro, M., 2013. Using Single-Source Data to DrivePrecise, Profitable Marketing. What's Next, 1(4), pp. 1-11.

xxi. RH.Ducoffe, 1995. How Consumers Assess the Value of Advertising. Journal of Current Issues \& Research in Advertising, 17(1), pp. 1-18.

xxii. $\quad$ S.Taylor \& Todd, P., 1995. Understanding information technology usage a test of competing models. Information Systems Research, 6(2), pp. 144-176.

xxiii. Sheppard, B., Hartwick, J. \& Warshaw, P., 1988. The theory of reasoned action:A metaanalysis of past research with recommendations and future research. Journal of Consumer Research, 15(3), pp. 325-343.

xxiv. Tabachnick, B. \& Fidell, L., 2007. Using Multivariate Statistics. 5th ed ed. New York: Allyn and Bacon.

xxv. Venkatesh, V. \& Davis, F., 2000. A Theoretical Extension of the Technology AcceptanceModel: Four Longitudinal Field Studies.. Management Science, 46(2), pp. 186-204.

xxvi. Venkatesh, V., Morris, M., Davis, F. \& Davis, G., 2003. User Acceptance of Information Technology :Toward a Unified View. MIS Quarterly, 27(3), pp. 425-478.

xxvii. Wallace, T., 2017. How Modern Consumer Behavior Has Changed in the New Omni-Channel World. [Online] Available at: https://www.bigcommerce.com/blog/consumerbehavior [Accessed 14 May 2017].

xxviii. Wheaton, B., B.Muthen, Alwin, D. \& Summers, G., 1977. Assessing Reliability and Stability in Panel Models. Sociological Methodology, 8(1), pp. 84-136.

xxix. Wiedemann, J., 2015. Integrated Marketing Communication in Fashion. In: J. Strähle, ed. Converting Customersinto Promoters? Emotionalizing Fashion Retail. s.l.:s.n., pp. 256-288..

xxx. Yamada, T., Asahi, Y. \& Yuura, K., 2015. An Analysis of the Synergistic Effect in the Advertisement Between the Television Commercials and the Internet Commercials, International Conference onHuman Interface and the Management of Information HCI. s.l., Human Interface and theManagement of Information. Information and Knowledge in Context. Proceeding.

xxxi. Yoon, S. \& Kim, J., 2001. Is the Internet More Effective Than Traditional Media?FactorsAffecting the Choice of Media. Journal of Advertising Research, Volume 41, pp. 53-60.

xxxii. Zeithaml, V., 1988. Consumer Perceptions of Price, Quality, and Value: A Means-End Model and Synthesis of Evidence. Journal of Marketing, 57(7), pp. 2-22. 